\title{
Understanding Competing Theories of Negotiation
}

\author{
Jobn S. Murray
}

Theory is like a map describing a limited geographic area from a specific, functional perspective. Such a map helps the user understand at a glance the full dimension of the area being described, as well as determine the best plan or strategy for completing a stated project.

Theory, by defining comprehensive issues in a meaningful way and identifying the right questions to ask in support of a particular objective, provides the same benefits for its user. Again similar to a map, theory is best evaluated by a set of realistic standards. I believe there are three standards that are appropriate: a reasonably accurate description of the reality for which it is being presented; a useful description of the factors important to the person needing to take action; and a consistently good outcome achieved by the competent user.

Negotiation theorists appear to be deeply divided between proponents of competitive and problem-solving theories. Competitive theorists claim both a close approximation to the actual experience of negotiators and a general superiority of outcomes. Problem-solving theorists assert the prescriptive superiority of their mode of conflict resolution in terms of outcomes, although some profess that competitive theory describes reality more accurately.

Many teachers-and most students-of negotiation are confused by the often polemical dialogue between opposing theorists. Adding to this confusion is the lack of precision with which theorists and practitioners use the terms theory, strategy and style. Commentators representing separate disciplines have referred to many different negotiation theories and models: competitive and coordinative (Pruitt, 1981); competitive and cooperative (Williams, 1983); adversarial and problem-solving (Menkel-Meadow, 1984); hard, soft and principled (Fisher and Ury, 1981); distributive and integrative (Raiffa, 1982); and functional and developmental models of negotiating behavior (Gulliver, 1979).

Although these multiple references appear to sift naturally into the two competing camps that I am calling competitive and problem-solving, the confusion remains. Are there really two competing theories that explain realities in the negotiation setting? Should there be just one? If there are two, do the strategies that each favors necessarily conflict? What behavioral characteristics does each explain, and what are the downside risks that are hidden within each?

John S. Murray is a Professor of Law at Texas Tech University, Lubbock. Texas, 79409. He is a member of the Board of Directors of The Conflict Clinic, Inc., the negotiation/mediation clinic affiliated with the Program on Negotiation at Harvard Law School. 
The following is an attempt to sketch a theoretical map that is both accurate for purposes of understanding the negotiating situation and descriptive in a way that is useful to the practicing negotiator. For purposes of evaluating possible outcomes, I have assumed a high level of negotiator competence, whether competitive or problem-solving (Williams, 1983, p. 41).

\section{Recognized Patterns}

Most negotiators, particularly lawrers, exhibit two distinct behavioral paterns. Table 1 lists some of the more obvious characteristics attached to each of these patterns.

TABLE 1

RECOGNIZED PATTERNS OF NEGOTIATORS

\begin{tabular}{|c|c|}
\hline Competitive & Problem-Solving \\
\hline $\begin{array}{l}\text { The negotiator: } \\
\text { Tries to maximize tangible resource } \\
\text { gains for own client within limits of current } \\
\text { dispute-problem. }\end{array}$ & $\begin{array}{l}\text { The negotiator: } \\
\text { Tries to maximize returns for own client } \\
\text { including any joint gains available. }\end{array}$ \\
\hline $\begin{array}{l}\text { Makes high opening demands and is slow to } \\
\text { concede. }\end{array}$ & Focuses on common interests of parties. \\
\hline Uses threats, confrontation, argumentation. & $\begin{array}{l}\text { Tries to understand the merits as objectively } \\
\text { as possible. }\end{array}$ \\
\hline $\begin{array}{l}\text { Manipulates people and the process. } \\
\text { Is not open to persuasion on substance. }\end{array}$ & $\begin{array}{l}\text { Uses nonconfrontational debating techniques. } \\
\text { Is open to persuasion on substance. }\end{array}$ \\
\hline $\begin{array}{l}\text { Is oriented to quantitative and competitive } \\
\text { goals. }\end{array}$ & $\begin{array}{l}\text { Is oriented to qualitative goals; a fair/wise/ } \\
\text { durable agreement, efficiently negotiated. }\end{array}$ \\
\hline
\end{tabular}

An effective and dramatic way to appreciate the differences between the two patterns is to see them reflected in the writings of their respective proponents. In support of the competitive pattern, James J. White, commenting on a draft of the new Model Rules of Professional Conduct for lawyers, wrote:

A final complication in drafting rules about truthfulness arises out of the paradoxical nature of the negotiator's responsibility. On the one hand the negotiator must be fair and truthful; on the other he must mislead his opponent.... The critical difference between those who are successful negotiators and those who are not lies in this capacity both to mislead and not to be misled.

Some experienced negotiators will deny the accuracy of this assertion, but they will be wrong... . To conceal one's true position, to mislead an opponent about one's true settling point, is the essence of negotiation (White, 1980, p. 927).

In support of problem-solving, Roger Fisher and William L. Ury conclude their book Getting to YES by stating:

In most instances to ask a negotiator, "Who's winning?" is as inappropriate as to ask who's winning a marriage. If you ask that question about your marriage, you have already lost the more important negotiation-the one about what kind of game to play, about the way you deal with each other and your shared and differing interests. 
This book is about how to "win" that important game-how to achieve a better process for dealing with your differences (Fisher and Ury, 1981, p. 154).

The patterns are easily recognizable. The stereotypical competitive negotiator is a zealous advocate: tough, clever, thorough, articulate, unemotional, demanding, aggressive and unapproachable-a Sylvester Stallone-"Rambo" type who achieves victory by defeating the opponent. The problem-solver is also thorough and articulate, but in addition: personable, cooperative, firm, principled, concerned about the other side's interests, and committed to fairness and efficiency - a Jimmy Stewart-"Mr. Smith Goes to Washington" approach to resolving disputes amicably. Even terminology reflects the distance between the patterns. A competitive bargainer, for instance, negotiates against an opponent; a problem-solver negotiates uith the other side.

\section{Basic Assumptions}

The gap between these recognized patterns suggests that negotiators who exhibit either type of behavior are operating under sets of different assumptions about the nature of the negotiating world. Table 2 lists some of the principal assumptions.

\section{TABLE 2}

BASIC ASSUMPTIONS

\begin{tabular}{|c|c|}
\hline Competitive & Problem-Solving \\
\hline $\begin{array}{l}\text { Negotiating world is controlled by egocentric } \\
\text { self-interest. }\end{array}$ & $\begin{array}{l}\text { Negotiating worid is controlled by enlightened } \\
\text { self-interest. }\end{array}$ \\
\hline $\begin{array}{l}\text { - underlying motivation is competitive/ } \\
\text { antagonistic. }\end{array}$ & - common interests valued. \\
\hline - limited resources. & - interdependence recognịzed. \\
\hline $\begin{array}{l}\text { - independent choices: tomorrow's decision } \\
\text { unaffected materially by today's. }\end{array}$ & $\begin{array}{l}\text { - limited resources with unlimited variation in } \\
\text { personal preferences. }\end{array}$ \\
\hline $\begin{array}{l}\text { Resource distribution system is distributive in } \\
\text { nature (either-or). }\end{array}$ & $\begin{array}{l}\text { Resource distribution system is integrative in } \\
\text { nature (joint). }\end{array}$ \\
\hline $\begin{array}{l}\text { Goal: win as much as you can-and especially } \\
\text { more than the other side. }\end{array}$ & $\begin{array}{l}\text { Goal: mutually agreeable solution that is fair to } \\
\text { all parties and efficient for community. }\end{array}$ \\
\hline
\end{tabular}

The competitive negotiator views the negotiating world as one controlled by an egocentric self-interest. This world is made up of limited resources that are divided by highly competitive people in a succession of independent transactions. The distribution system for these limited resources is fundamentally distributive in nature, presenting each person with an either-or choice. The competition is for the resource dollar. There is no sharing the last dollar; either one negotiator or the other gets it. The goal is victory-to win as much as possible, and especially more than the opponent. The negotiating atmosphere in such a world is divisive, tense, game-like, and transactional.

To the problem-solver, the negotiating world is controlled by an enlightened self-interest. The negotiator values the common interests that bind parties together within an interdependent system. Although self-interest is reflected in the recognition of limited resources, the problem-solver sees an unlimited variation in individual preferences among the resources. The dollar 
may be a scarce resource desired by both negotiators, but each values that dollar differently. The distribution system, therefore, is fundamentally integrative in nature, with each party maximizing joint gains based upon their individual value preferences. The goal is a mutually agreeable solution to the dispute or problem, a solution that balances fairness for all parties and is efficient for the community.

\section{Explanation of Negotiating Behavior}

Each of these views has a significant and distinct impact on the behavior of negotiators who accept it.

The competitive negotiator appears to have a narrow perspective on the negotiation as a whole, but broad and flexible standards for selecting strategies and manipulating the process. Competitive theory is reflected in behavior when the negotiator:

1. Maximizes own return in present transaction.

2. Considers needs/interests/attitudes of opponent as not legitimate, and only relevant when usable to achieve $\# 1$ above.

3. Views all disputing processes and strategies as equally valuable and useful if helpful in achieving \#1 above.

4. Behaves cooperatively only if it helps achieve \#1 above.

5. Chooses processes and strategies similar to military maneuvers. The focus is on the process of winning, not on the resolution of disputes.

6. Presents a strong defense against opponent's tactics.

7. Must control the negotiating process for proper manipulation.

The problem-solving negotiator. on the other hand, holds a broad perspective on the negotiation as a whole, combined with more rigid limits on acceptable strategies and conduct. Some of the key behavioral elements for the problem-solver are:

1. Maximizes own return within the larger time and community context.

2. Considers needs/interests/attitudes of other side as both relevant and legitimate to resolving the dispute.

3. Is competitive but not antagonistic.

4. Tries to discover and share any joint gains available.

5. Concentrates on the substance of the dispute or decision.

6. Considers negotiation and other voluntary processes as superior to nonvoluntary methods (adjudication).

These separate behavioral characteristics contain significant strengths within the bargaining situation. The competitive negotiator can be focused and single-minded, with no details being materially relevant other than the present dispute and the party/client. This concentration allows the competitive negotiator to prepare fully for a specific settlement conference. He or she can come armed with a solid offer and fixed negotiation strategies. The opponent's perspective and tactics will not affect the opening position or strategies; they are important only for the manner and rate of concessions, should the negotiator decide to make any at all. Such knowledge gives the negotiator a reassuring sense of control that translates into confidence that is 
impressive in the negotiation setting.

Another strength follow's directly from this disregard for the opponent's position and tactics. The competitive negotiator has analyzed the facts, determined the position, and made the case. The opponent cannot dislodge or defeat this preparation by any means of persuasion based on the merits. Having such an unbreachable defensive position permits the competitive negotiator to stress an aggressive offense aimed at persuading, coercing, deceiving or otherwise manipulating the opponent to an acceptable agreement.

There is also strength in the competitive negotiator's flexibility in selecting strategies. Everything is acceptable, including the alternative of not negotiating, with the only limit being the express violation of ethical obligations. The ultimate selection is based directly on which strategy yields the maximum expected gain for the party/client. A significant element of bargaining power is the attractiveness of a good alternative to negotiating with the opponent. The competitive negotiator does not hesitate to choose that alternative when it is perceived as yielding a bigger gain, even if that choice places the party/client in a psychologically costly court trial. The relevant standards are quantitative: the size of gain expected from the alternative, discounted to reflect any time delay, compared to what appears possible in settlement. The competitive negotiator thereby avoids the confusion and indecision fostered by the impact of intangible or psychological factors and the normative arguments of fairness, wisdom, durability, and efficiency.

Finally, there is psychological strength in the excitement of doing battle. Like a military general, the competitive negotiator concentrates full attention on manipulating the tools and processes available within the negotiation setting. The goal is victory over the opponent on the field of battle. Resolving the underlying disagreements between parties/clients is left to others. With no responsibility for resolving these underlying problems, the negotiator can savor the excitement and challenge of the negotiation chase as if it were only a game, like baseball, chess or poker.

On the other side, the problem-solving negotiator also brings strengths to the bargaining table. Concentration on the merits of the dispute gives the problem-solver a sense of legitimacy, centrality and purpose. The problemsolver is responsible not only for tactical decisions within the negotiation setting but also for helping resolve the underlying problems of the party/ client. Such a central role to the life of the party/client makes the negotiator's efforts less like a game and more like a serious human responsibility. In addition, using the merits as the central negotiating focus establishes a more objective and predictable control mechanism than can be achieved by relying on manipulation of the personal strategy and style decisions of the negotiators.

The problem-solving negotiator also generates strength by recognizing the importance of common interests and joint gains. Such objectives can be shared among negotiators and parties/clients in a mutually positive and reinforcing way, quite different than the competitive effect that the goal of victory has.

Finally, successful problem-solving is a satisfying experience on a human level. Since the intended outcome of the negotiation is a win-win result; the accomplishment of creating an innovative solution that maximizes joint as 
well as individual gains can be shared with the other side. The process of reaching this goal is psychologically unifying, rather than divisive. Negotiating is thus an enjoyable and challenging personal experience, rather than a highly stressful battle of wits and words.

\section{Downside' Risks}

Each behavioral pattern exhibits weaknesses as well as strengths. Table 3 lists the downside risks that negotiators accepting each theory meet. The significance of recognizing these risks lies in understanding negotiator vulnerabilities, identifying possible threats to consistently good outcomes, and developing appropriate responses or changes to improve the result.

\section{TABLE 3 DOWNSIDE RISKS}

Competitive:

1. Strong bias toward confrontation, encouraging the use of coercion and emotional pressure as persuasive means: hard on relationships, breeding mistrust, feelings of separateness, frustration and anger, resulting in more frequent breakdowns in negotiations; and distorts communication, producing misinformation and misjudgment.

2. Guards against responsiveness and openness to opponent (defensive), thereby restricting access to joint gains.

3. Encourages brinkmanship by creating many opportunities for impasse.

4. Increases difficulty in predicting responses of opponent because reliance is on manipulation and confrontation to control process.

5. Contributes to overestimation of return possible through alternatives (court) because focus is not on a relatively objective analysis of substantive merits as standard for resolution.

\section{Problem-Solving:}

1. Strong bias toward cooperation, creating internal pressures to compromise and accommodate.

2. Avoids strategies that are confrontational because they risk impasse, which is viewed as failure.

3. Focuses on being sensitive to other's perceived interests: increases vulnerability to deception and manipulation by a competitive opponent; and increases possibility that settlement may be more favorable to other side than fairness would warrant.

4. Increases difficulty of establishing definite aspiration levels and bottom lines because of reliance on qualitative (value-laden) goals.

5. Requires substantial skill and knowledge of process to do well.

6. Requires strong confidence in own assessment powers (perception) regarding interests/needs of other side and other's payoff schedule.

It is especially enlightening to analyze the downside risks with the objective of devising actions that might decrease or eliminate them. For the competitive negotiator, adopting actions intended to lessen the risks appears to change negotiating behavior from a competitive to a problem-solving mode.

For example, actions aimed at reducing the harmful effects of frustration, anger, mistrust, misinformation and misjudgment must of necessity include building a better working relationship between the negotiators. The objective would be to identify and eliminate possible breakdowns that are based on emotional and communication problems and not due to the inability to find an outcome that maximizes the party/client gain. The result of adopting such actions would be to improve the amount and credibility of information exchanged, increase the grounds for trust, and lessen the use of manipulation based on process rather than substance.

The success of misrepresentation and deceit as a strategy to elicit infor- 
mation leading to joint gains depends largely on an inequality in the relative level of negotiator competence, which is not a solid base for generating consistently good outcomes. Therefore, actions intended by the competitive negotiator to uncover joint gains would need to include improvement in active listening and acceptance of the opponent's legitimacy.

Reducing brinkmanship would help eliminate impasses where settlement at the party/client's maximum is possible but is frustrated by the psychological impact of the frequent use of threats. Pulling back from the brink requires fewer threats of impasse, less psychological tension, and more recognition of substantive fairness.

The competitive negotiator who tries to counter these downside risks becomes more problem-solving than competitive in orientation, thereby exhibiting more of the characteristics and strengths associated with problemsolving theory.

On the other side, analysis of the downside risks of problem-solving theory suggests that corrective actions will lead to a strengthening of problem-solving skills, not to a change in basic negotiating behavior. The theories are in this way asymmetrical.

For example, the tendency toward unwarranted compromise and accommodation is countered not by confrontation and stubbornness but by more thorough preparation on the merits and a stronger commitment to an identifiable substantive standard (Pruitt and Lewis, 1977, p. 183). Indefinite aspiration levels and bottom lines pose serious problems for the problemsolving negotiator at all stages of negotiation, from the initial planning to postagreement evaluation. Corrective steps include the development and use of more accurate analysis of the subject matter, not a shift to process manipulation and positional bargaining

Viewing impasse not as failure but as a better alternative than agreeing to an unfair settlement does not force a negotiator to be confrontational in a competitive sense. Rather, it causes the problem-solver to be even more committed to a recognized standard of fairness and more flexible in strategy selection.

One of the most feared downside risks for the problem-solver is vulnerability to deception and manipulation by a competitive opponent. The result can be not only an inequitable outcome but also a residual sense of personal and professional embarrassment. Reciprocating with equally deceptive and competitive behavior may be the easiest response, but such reciprocity is defensive in nature, not corrective. Actions to detect and counter deception and manipulation must focus on ways to build confidence in the truthfulness of information exchanged and in the identification of various negotiating tactics.

Personal confidence in the negotiator's own ability and judgment is a prerequisite for effective problem-solving. The negotiator builds such confidence by acquiring up-to-date knowledge of both substance and process, preparing rigorously for each case, and seeking practical negotiating experiences.

Negotiation for the problem-solver who tries to correct for downside risks does not shift to a more competitive and confrontational mode but rather retains and enhances problem-solving characteristics. 


\section{Conclusion}

Current thought accepts the notion that there are two exclusive and competing theories that explain negotiation behavior: the competitive and problem-solving theories. Each theory has certain basic assumptions that appear to establish it as unique. The resulting behavior of negotiators who accept each set of assumptions has characteristics that are identifiable and important within the negotiation setting.

An analysis of the downside risks of each of these theories, however, raises some question about their uniqueness. As attempts are made to improve negotiator performance within each, the problem-solving theory becomes dominant. This result appears incompatible with the conclusion of some empirical studies of negotiator effectiveness (Williams, 1983), but the difficulty of defining and measuring effectiveness is widely recognized. The analysis in this article suggests that the more proficient a negotiator becomes under either theory, the more his or her behavior will reflect the elements of problem-solving theory.

The conclusion may be unavoidable that only the problem-solving theory satisfies all three quality standards for a general theory: it describes negotiation realities with reasonable.accuracy, is useful in developing strategies, and provides consistently good outcomes for the competent negotiator. The recognizable competitive variant may just reflect different negotiator personality and style characteristics, and the quality and consistency of outcomes may depend partly on the relative levels of negotiator competence.

\section{REFERENCES}

Fisher, R. and Ury, W.L. Getting to YES: Negotiating Agreement Without Gil'ing In. Boston: Houghton Mifflin, 1981.

Gulliver, P. H. Disputes and Negotiations: A Cross-Cultural Porsfertive. New York: Academic Press, 1979.

Menkel-Meadow, C. "Toward Another View of Negotiation: The Structure of Legal ProblemSolving." UCLA Lau' Ret'ieu' 31 (1984):75+

Pruitt, D.G. Negotiating Bebaitior. New York: Academic Press, 1981.

---- and Lewis, S.A. In Negotiations: Social-Psychological Perspectives, ed. D. Druckman. Beverly Hills, Calif.: Sage, 1977.

Raiffa, H. The Art and Science of Negotiation. Cambridge, Mass.: Harvard University Press, 1982 ,

Williams, G.R. Legal Negotiation and Settlement. St. Paul: West. 1983.

White, J.J. "Machiavelli and the Bar: Ethical Limitations on Lying in Negotiation." American Bar Foundation Research Journal 80 (Fall 1980):926. 